\title{
Investigation of Deformation Mechanisms in Deep-Drawn and Tensile-Strained Austenitic Mn-Based Twinning Induced Plasticity (TWIP) Steel
}

\begin{abstract}
R.T. VAN TOL, L. ZHAO, H. SCHUT, and J. SIETSMA
The effect of strain on the deformation mechanisms in an austenitic Mn-based twinning induced plasticity (TWIP) steel is investigated using magnetic measurements, XRD, positron beam Doppler spectroscopy, and finite element method simulations. The experimental observations reveal the formation of $\alpha^{\prime}$-martensite at specific degrees of deformation, despite the high stacking fault energy (SFE) of the material $\left(52 \mathrm{~mJ} / \mathrm{m}^{2}\right)$. The observed fraction $\alpha^{\prime}$-martensite is consistent with the estimated fraction of intersected shear bands acting as preferred nucleation sites for $\alpha^{\prime}$-martensite formation as a function of accumulated equivalent strain.
\end{abstract}

DOI: $10.1007 / \mathrm{s} 11661-012-1123-7$

(C) The Author(s) 2012. This article is published with open access at Springerlink.com

\section{INTRODUCTION}

IN order to improve safety and fuel economy, the use of advanced high strength steels in the automotive industry has increased significantly in the last decade. One of the latest developments is austenitic Mn-based twinning induced plasticity (TWIP) steels, which combine high strength with high ductility. These superior mechanical properties are a result of deformation mechanisms involving twinning or plasticity-induced transformation $^{[1-6]}$ related to the austenite $(\gamma)$ stability. The deformation mechanisms in these Mn-based TWIP steels have been most intensively investigated for tensile straining, ${ }^{[3-6]}$ leaving the role of large strain on the twinning or transformation-induced plastic deformation mechanism less exposed. ${ }^{[7]}$ In the present work, the effect of both deep drawing and tensile straining on the defect and microstructure evolution in Mn-based TWIP steels was experimentally investigated using magnetic measurements, X-ray diffraction (XRD), and positron annihilation. The strain evolution during deep drawing was simulated by means of finite element methods.

\section{EXPERIMENTAL}

The examined material was a Mn-based TWIP steel grade that is austenitic at room temperature. Table I shows the chemical composition of this steel. The stacking fault energy (SFE) amounts to $52 \mathrm{~mJ} / \mathrm{m}^{2}$, based on the

R.T. VAN TOL, Principal Researcher, is with Tata Steel Research Development \& Technology, 1970 CA IJmuiden, The Netherlands. Contact e-mail: ron.van-tol@tatasteel.com L. ZHAO, Scientific Researcher, is with the Materials Innovation Institute, 2628 CD Delft, The Netherlands, and is also with the Department of Materials Science and Engineering, Delft University of Technology, 2628 CD Delft, The Netherlands. H. SCHUT, Scientific Researcher, is with the Faculty of Applied Sciences, Delft University of Technology. J. SIETSMA, Professor, is with the Department of Materials Science and Engineering, Delft University of Technology.

Manuscript submitted August 31, 2011.

Article published online May 1, 2012 thermodynamic approach proposed by Bleck et al. ${ }^{[8]}$ with empirical coefficients for $\mathrm{Si}\left(-7 \mathrm{~mJ} / \mathrm{m}^{2}\right.$ per wt pct $\mathrm{Si})^{[9]}$ and $\mathrm{Al}\left(+10 \mathrm{~mJ} / \mathrm{m}^{2}\right.$ per wt pct Al $) \cdot{ }^{[10]}$ Note that this calculated value is estimated to be accurate within $\pm 10 \mathrm{~mJ} / \mathrm{m}^{2}$.

The material was cold rolled to a thickness of $1.7 \mathrm{~mm}$ and then recrystallized. Table I also shows the mechanical properties after recrystallization. The cold-rolled and recrystallized sheets were cut into round blanks with a diameter of $102.5 \mathrm{~mm}$ using water jet cutting technology. The blanks were formed into cups by deep drawing on an Erichsen press (Tata Steel Research Development \& Technology, IJmuiden, The Netherlands) with a ratio of blank diameter to punch diameter of 2.05. Table II shows the other deep-drawing parameters. Standard A80 tensile samples, according to the Euro-norm, were strained up to 10, 20, 30, and 40 pct using a Zwick tensile tester (Tata Steel Research Development \& Technology, IJmuiden, The Netherlands).

Scanning electron microscopy (SEM) was performed on a Zeiss Ultra 55 field emission gun scanning electron microscope to characterize the microstructure. The microscope was equipped with an in-lens electron optic system. Specimens were mounted in Polyfast resin, which was electrically conductive with low emission in the vacuum chamber during examination. All micrographs were obtained using a beam of $15 \mathrm{keV}$ electrons. Figure 1 shows the microstructure in the undeformed condition and after deep drawing taken at 20 and $40 \mathrm{~mm}$ from the cup bottom. The undeformed microstructure is fully recrystallized, with an equi-axial austenite grain size of about $5 \mu \mathrm{m}$. Upon straining, micro shear bands appear in some of the grains. It is believed that the majority of these bands are microtwins, even though a more detailed, diffraction-based study is required to prove this. At $20 \mathrm{~mm}$ from the cup bottom, the microstructure is dominated by primary shear bands (Figure 1(b)). At very high strains (Figure 1(c)), clear distinction between individual shear bands is no longer possible.

Finite-element method simulations were performed to calculate the true local major and minor strain resulting 
Table I. Composition and Mechanical Properties of Mn-Based TWIP Steel

\begin{tabular}{|c|c|c|c|c|c|c|c|}
\hline $\mathrm{C}(\mathrm{Wt}$ Pct $)$ & $\mathrm{Si}$ (Wt Pct) & Mn (Wt Pct) & $\mathrm{Al}$ (Wt Pct) & $R p \quad(\mathrm{MPa})$ & $R m(\mathrm{MPa})$ & $\mathrm{Ag}(\mathrm{Pct})$ & A80 (Pct) \\
\hline 0.71 & 0.07 & 14.55 & 2.93 & 508 & 875 & 42.1 & 45.5 \\
\hline
\end{tabular}

Table II. Deep-Drawing Parameters

Blank holder force $(\mathrm{kN})$

Punch speed $(\mathrm{mm} / \mathrm{s})$

Punch diameter (mm)

Punch edge radius ( $\mathrm{mm})$

Die diameter (mm)

Die edge radius $(\mathrm{mm})$

Lubrication

Temperature $\left({ }^{\circ} \mathrm{C}\right)$
20 to 30

1.5

50

7.5

54.8

6.0

Teflon foil 20 from deep drawing, using the Bergström-Van Liempt hardening rule and Vegter yield locus ${ }^{[1]}$ optimized for conventional steel grades. Pam-Stamp 2G calculations were carried out with the deep-drawing parameters given in Table II and the material input parameters given in Table I. Figure 2 shows the strain paths in terms of $\varepsilon_{1}$; the major true strain in axial direction; and $\varepsilon_{2}$, the minor true strain in tangential direction, for different degrees of tensile straining and deep drawing at

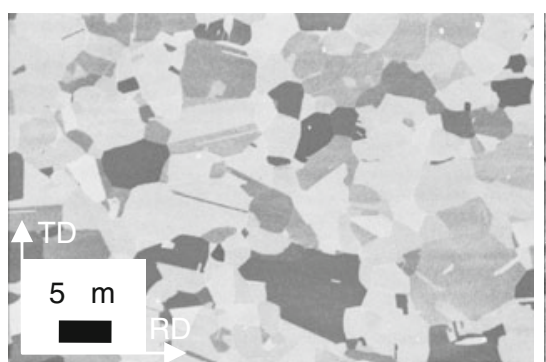

(a)

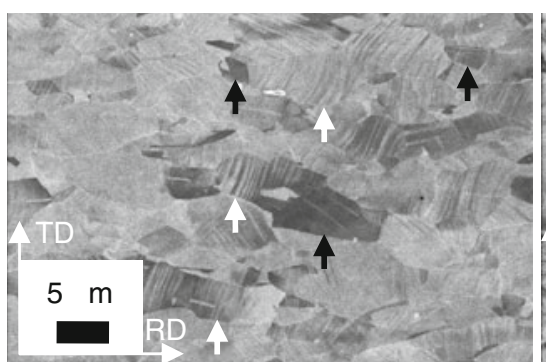

(b)

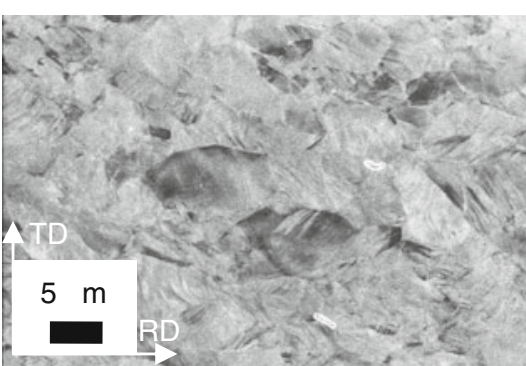

(c)

Fig. 1-Scanning electron micrographs: (a) prior to deep drawing, (b) deep drawn at $20 \mathrm{~mm}$, and (c) deep drawn at $40 \mathrm{~mm}$ from the cup bottom. The white thin arrows indicate the transverse and rolling directions. The white thick arrows indicate grains with typical shear bands. The black arrows indicate grains essentially without shear bands.

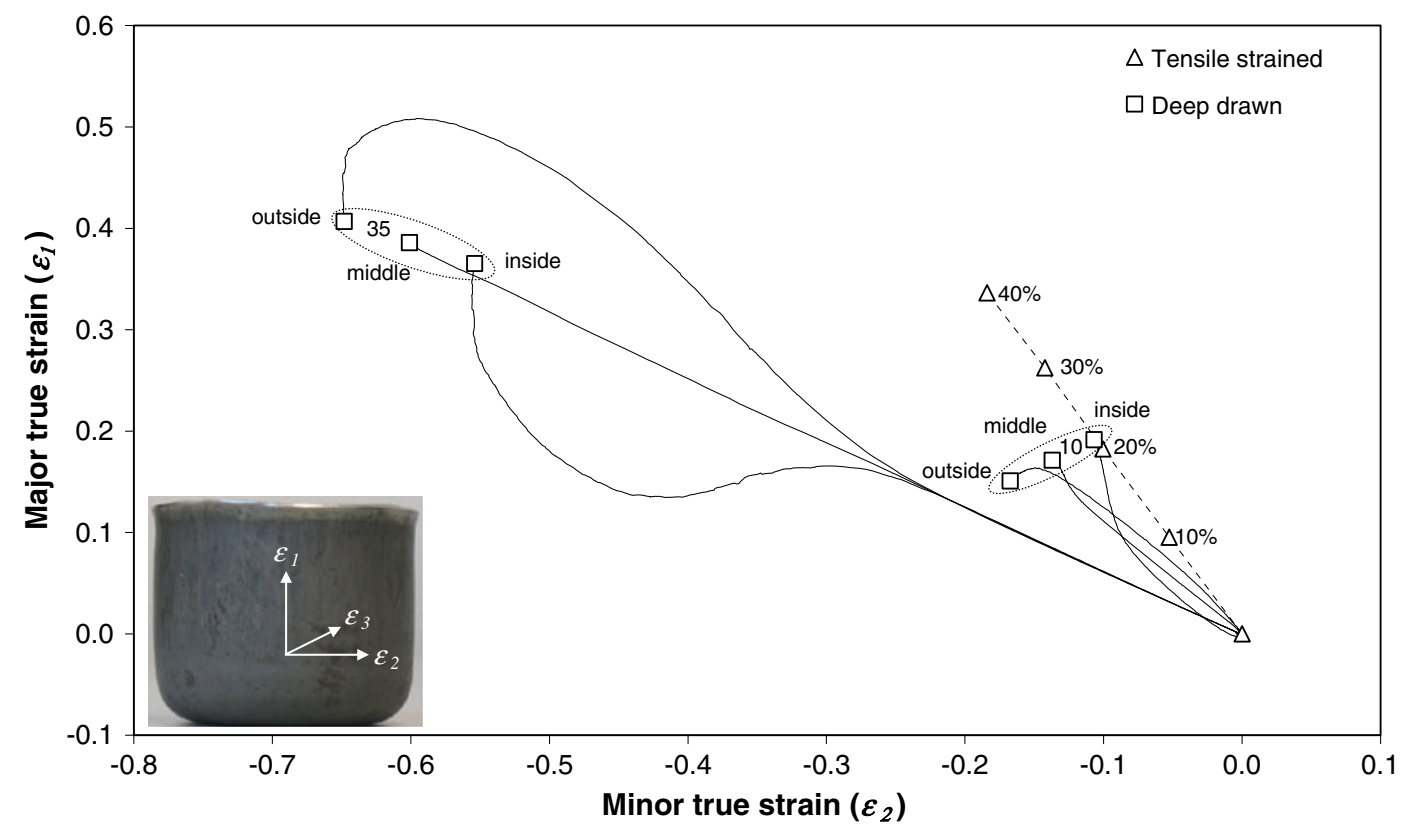

Fig. 2-Strain paths for tensile straining and deep drawing at 10 and $35 \mathrm{~mm}$ from the cup bottom at the inner side, middle, and outer side of the cup. The tensile strain (in pct) and the position from the deep-drawn cup bottom (in mm) are indicated. The inset shows an example of a deep-drawn cup and the directions of $\varepsilon_{1}$ (axial direction), $\varepsilon_{2}$ (tangential direction), and $\varepsilon_{3}$ (radial direction). 
the outer side, center, and inner side of the cup at $10 \mathrm{~mm}$ and at $35 \mathrm{~mm}$ from the cup bottom. $\varepsilon_{3}$ along the cup thickness in a radial direction is related to $\varepsilon_{1}$ and $\varepsilon_{2}$ according to the constraint

$$
\varepsilon_{1}+\varepsilon_{2}+\varepsilon_{3}=0
$$

With the use of Eq. [1], the accumulated equivalent strain $\left(\varepsilon_{e q}^{a c}\right)$, which will be used in this study as the characteristic strain parameter, is given by

$$
\varepsilon_{e q}^{a c}=\sqrt{4 / 3} \cdot \int_{0}^{\varepsilon} \sqrt{1+\rho+\rho^{2}} d \varepsilon_{1}
$$

with

$$
\rho=\frac{d \varepsilon_{2}}{d \varepsilon_{1}}
$$

The structural defects resulting from deep drawing were examined as a function of the position from the cup bottom (increasing $\varepsilon_{e q}^{a c}$ ), starting at $10 \mathrm{~mm}$ from the cup bottom up to $40 \mathrm{~mm}$ with 5 -mm intervals.

For the magnetization experiments, approximately cubic samples with a size of approximately $2 \mathrm{~mm} \times$ $2 \mathrm{~mm} \times d$, with $d$ being the thickness, were machined from the deep-drawn cup and tensile-strained specimens using an electrodischarging machine. The magnetization measurements were performed in a Lake Shore 7307 vibrating sample magnetometer (Materials Innovation Institute, Delft, The Netherlands), calibrated with a standard NIST nickel specimen. All magnetic samples were measured from -1.5 to $1.5 \mathrm{~T}$, a field high enough to reach the magnetic saturation for ferromagnetic phases in this steel. ${ }^{[12]}$ The weight fraction of $\alpha^{\prime}$-martensite - the only ferromagnetic phase present in this material - is determined by

$$
f\left(\alpha^{\prime}\right)=\frac{M_{s}}{x_{F e} M_{s, F e}}
$$

where $M_{s}$ is the sample magnetization, $M_{s, \mathrm{Fe}}$ is the measured magnetization of pure iron at room temperature $\left(215 \mathrm{Am}^{2} / \mathrm{kg}\right)$, and $x_{\mathrm{Fe}}$ represents the Fe fraction in the material. In the case of low fractions, the difference between weight and volume fractions can be considered negligible due to the small difference in density between austenite and $\alpha^{\prime}$-martensite.

XRD was performed using a Bruker-AXS D8 Discover diffractometer with Eulerian cradle (Delft University of Technology, Delft, The Netherlands). Co $K_{\alpha}$ radiation was used for conventional $\theta$ to $2 \theta$ scans. The diffraction patterns were recorded using a step size of $0.02 \mathrm{deg}$ in $2 \theta$, and the intensity was evaluated by the DIFFRAC ${ }^{\text {plus }}$ BASIC Evaluation Package 14 (Delft University of Technology, Delft, The Netherlands).

The deep-drawn and the tensile-strained samples were subjected to positron beam Doppler broadening spectroscopy, performed with the Delft variable energy positron (VEP) beam. ${ }^{[13]}$ Positrons emitted from a ${ }^{22} \mathrm{Na}$ source are-after moderation to thermal energy and subsequent controlled acceleration - injected in the samples and eventually annihilated with electrons in the material. The electron involved can either be a relatively free valence electron or a relatively strongly bound core electron. As a result of the conservation of energy and momentum, the annihilation results in the emission of two $\gamma$-quanta with energy of about $511 \mathrm{keV}$ each, emitted in (nearly) opposite directions. Due to the (positive or negative) momentum component of the electron in the direction of the $\gamma$ emission, the measured $\gamma$ energy is Doppler shifted, leading to a broadening of the $511 \mathrm{keV}$ photo peak. This broadening is quantified by the lineshape parameters $S$ and $W,^{[13,14]}$ of which the $S$ parameter ( $S$ for shape) is determined by annihilation with lowmomentum valence electrons and the $W$-parameter $(W$ for wing) is determined by annihilation with highmomentum core electrons. In general, for a positron trapped in a defect (such as a dislocation, a vacancy, or a vacancy cluster), the probability of annihilation with core electrons is reduced, resulting in a higher $S$-parameter value and a lower $W$-parameter value. At a positron energy of $25 \mathrm{keV}$, the positron beam probes a circular area with a radius of $4 \mathrm{~mm}$ at a depth of about $1 \mu \mathrm{m}$.

It is important to note that positron beam Doppler spectroscopy and XRD only probe the outer side of the cup (penetration depths 1 and $10 \mu \mathrm{m}$, respectively) at a specific position from the cup bottom, whereas the magnetization measurements concern the full thickness of the cup. For that reason, magnetization results are related to the average accumulated equivalent strain $\varepsilon_{e q}^{a c}$ over the cup thickness, whereas the XRD and positron annihilation results are related to $\varepsilon_{e q}^{a c}$ at the outer side of the cup.

\section{RESULTS}

Figure 3 shows the volume fraction of $\alpha^{\prime}$-martensite, determined from magnetic measurements as a function of $\varepsilon_{e q}^{a c}$ averaged over the cup thickness. There is an initial $\alpha^{\prime}$-martensite fraction of approximately 0.2 pct. Tensile straining does not affect the $\alpha^{\prime}$-martensite fraction. Deep drawing promotes the formation of $\alpha^{\prime}$-martensite, leading to significant increase of the fraction for $\varepsilon_{e q}^{a c} \geq 0.6$. It is worth noting that at $35 \mathrm{~mm}$ from the cup bottom, the maximum volume fraction is about 0.7 pct, an amount too small to be detected by XRD.

Figure 4 presents the integral breadth of the $\{111\}$, $X R D$ reflection, the most accurately determined reflection, as a function of $\varepsilon_{e q}^{a c}$ at the outer side of the cup. The increase of tensile strain clearly increases the integral breadth. Increased straining during deep drawing initially increases the integral breadth in a similar way, followed by saturation for $\varepsilon_{e q}^{a c} \geq 0.6$. This increase in integral breadth prior to the formation of $\alpha^{\prime}$-martensite (see Figure 3) indicates dislocation multiplication or twinning. Straining at $\varepsilon_{e q}^{a c} \geq 0.5$ induces the formation of $\alpha^{\prime}$-martensite by allowing the passage of previously blocked dislocations. ${ }^{[15,16]}$ At $\varepsilon_{e q}^{a c} \geq 0.6$, $\alpha^{\prime}$-martensite formation becomes the dominant deformation mechanism, which does not cause a further increase of the integral breadth. Later in this article, positron beam Doppler data will enable us to distinguish the different deformation mechanisms already indicated in Figure 4.

Figure 5 shows the $W-S$ map for deep drawing and tensile straining in which the $S$ and $W$ parameters are 


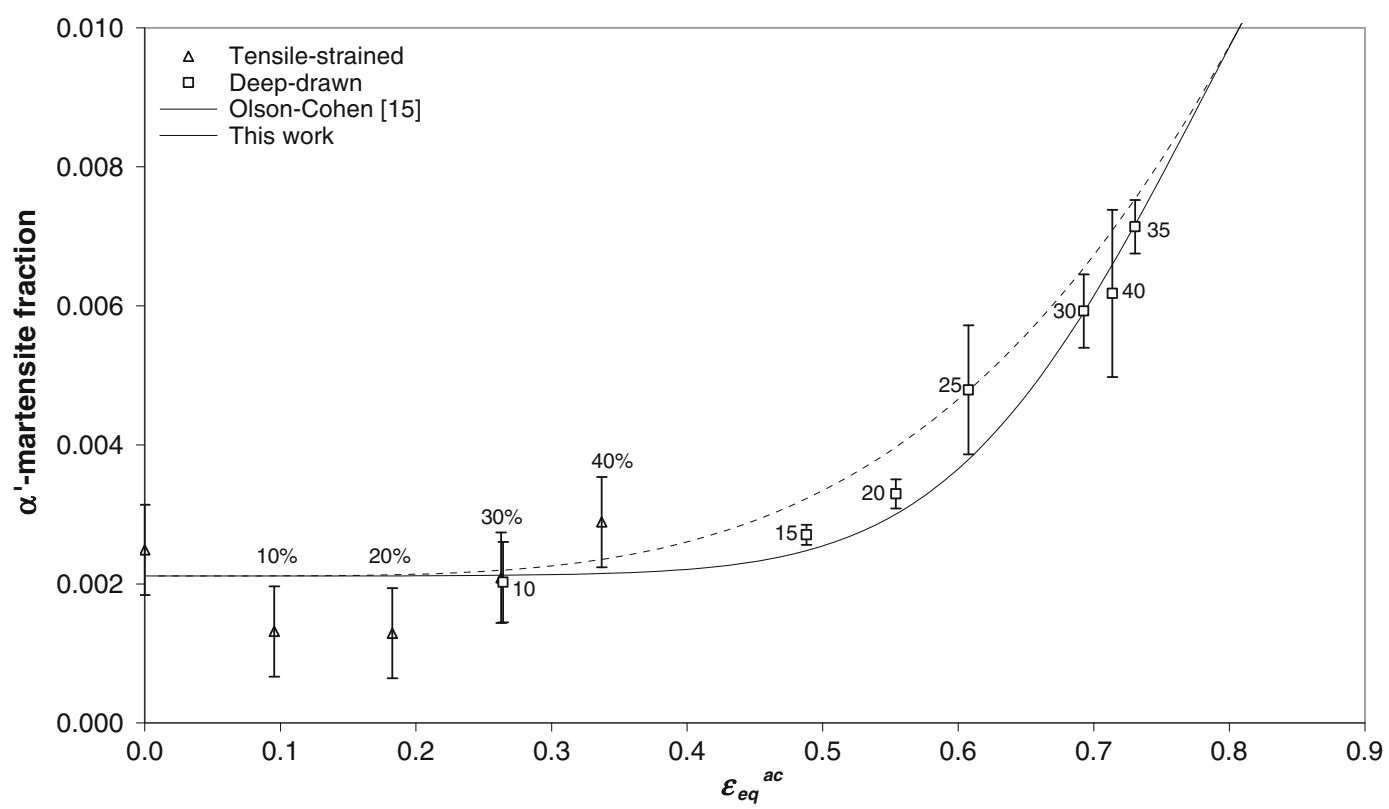

Fig. 3- $\alpha^{\prime}$-Martensite fraction, determined by magnetic measurements, for deep drawing and tensile straining as a function of $\varepsilon_{e q}^{a c}$ averaged over the cup thickness. The tensile strain (in pct) and the position from the deep-drawn cup bottom (in $\mathrm{mm}$ ) are also indicated.

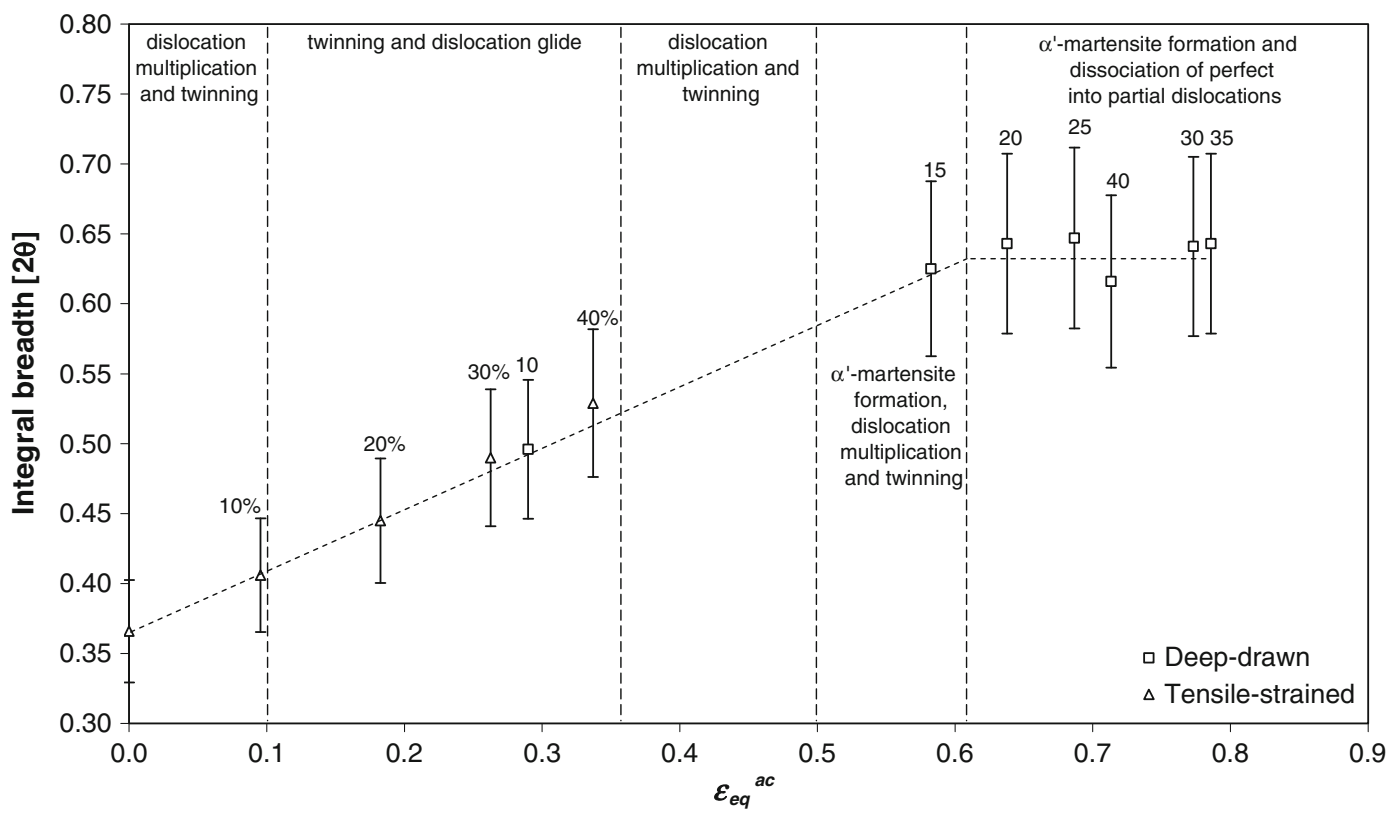

Fig. 4 -Integral breadth of the $\{111\}$, reflection in XRD for deep drawing and tensile straining as a function of $\varepsilon_{e q}^{a c}$ at the outer side of the cup. The tensile strain (in pct) and the position from the deep-drawn cup bottom (in mm) are also indicated. Deformation mechanisms are schematically indicated.

normalized with respect to the annealed material, $S_{b}$ and $W_{b}$. Previous work ${ }^{[17]}$ on positron beam Doppler spectroscopy on the present steel revealed the existence of two defect types $D_{1}$ and $D_{2}$. With characteristic $S-W$ values $\left(S_{D 1} / S_{b}=1.052, W_{D 1} / W_{b}=0.870\right)$ for defect $D_{1}$ and $\left(S_{D 2} / S_{b}=1.037, W_{D 2} / W_{b}=0.860\right)$ for defect $D_{2}$, the fractions of positrons trapped at these defects, $\eta_{1}$ and $\eta_{2}$, were calculated, assuming two defect trapping states and using

$$
\frac{S}{S_{b}}=\left(1-\sum_{i=1}^{2} \eta_{i}\right)+\sum_{i=1}^{2} \eta_{i} \cdot \frac{S_{d i}}{S_{b}}
$$

Equation [4] can be defined in an analogous manner for the $W$ parameter. In the previous work, ${ }^{[17]}$ the larger defect type $D_{1}$ was attributed to perfect dislocations, whereas the smaller defect type $D_{2}$ was attributed to partial dislocations. 


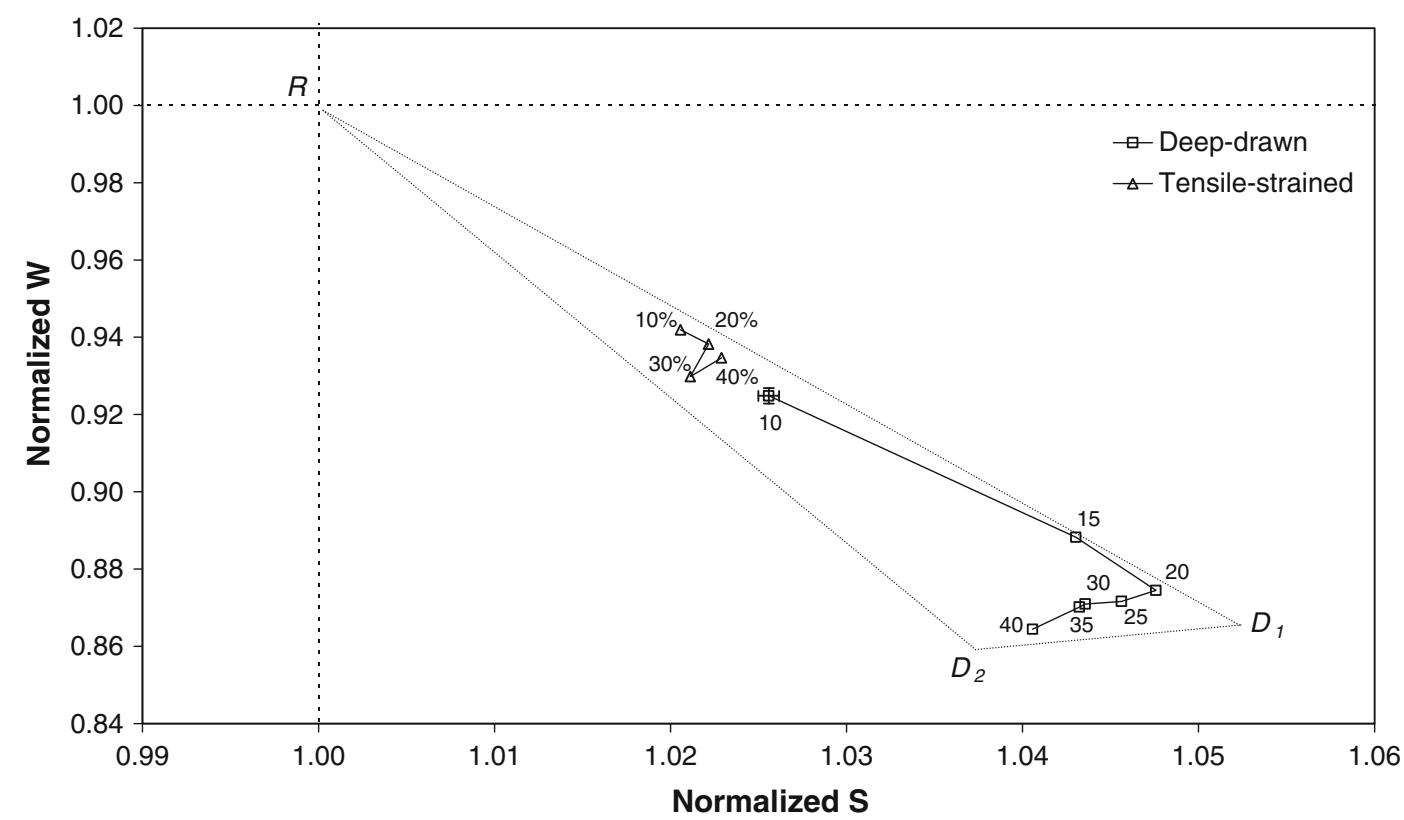

Fig. 5-W-S map for austenitic Mn-based TWIP steel cups for deep drawing and tensile straining. $R$ is the reference point, and $D_{1}$ and $D_{2}$ are defect types (Ref. 13). The tensile strain (in pct) and the position from the deep-drawn cup bottom (in mm) are also indicated.

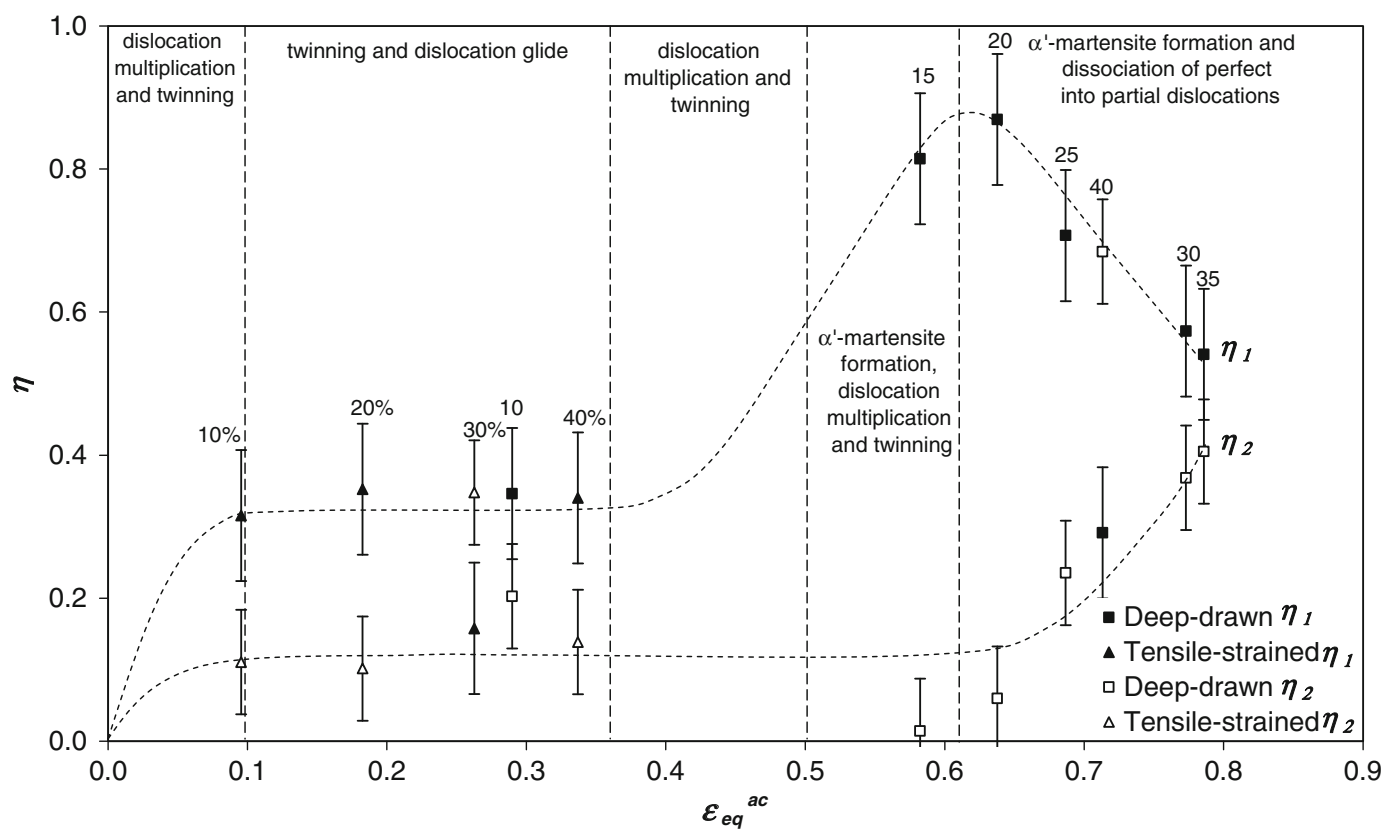

Fig. 6-Fraction $\left(\eta_{1}\right.$ and $\eta_{2}$ ) of positrons trapped at defect type $D_{1}$ (perfect dislocation ${ }^{[17]}$ ) and $D_{2}$ (partial dislocation ${ }^{[17]}$ ) resulting from positron beam Doppler spectroscopy as a function of $\varepsilon_{e q}^{a c}$ at the outer side of the cup for deep drawing and tensile straining. The tensile strain (in pct) and the position from the deep-drawn cup bottom (in $\mathrm{mm}$ ) are also indicated.

The positron annihilation results enable a further distinction of deformation mechanisms prior to and during $\alpha^{\prime}$-martensite formation. Figure 6 shows $\eta_{1}$ and $\eta_{2}$ as a function of $\varepsilon_{e q}^{a c}$ at the outer side of the cup. At $\varepsilon_{e q}^{a c} \approx 0.1$ to 0.4 , positron annihilation reveals no change in trapping fractions $\eta_{1}$ and $\eta_{2}$, excluding dislocation multiplication and indicating twinning and dislocation glide as the dominant deformation mechanisms. ${ }^{[18]}$ These twins and their intersections act as barriers for further dislocation glide and eventually immobilize dislocations. Further straining requires dislocation multiplication and results in high stress concentrations at shear bands and their intersections, as evidenced by an increasing trapping fraction $\eta_{1}$ at $\varepsilon_{e q}^{a c}$ up to 0.6. Once these high stress concentrations enable the passage of previously blocked (immobilized) dislocations and induce $\alpha^{\prime}$-martensite formation (Figure 3), there is no need for further dislocation multiplication (as observed in Figure 4). At this 
stage, the positron annihilation results disclose that the formation of $\alpha^{\prime}$-martensite leads to a decreasing $\eta_{1}$. The simultaneous increase in $\eta_{2}$ indicates the formation of energetically more favorable partial dislocations enabling further relaxation of the internal stresses caused by the $\alpha^{\prime}$-martensite formation due to the lower density of $\alpha^{\prime}$-martensite in comparison to the original microstructure. These partial dislocations could originate from the dissociation of perfect dislocations, since both the integral breadth and the total defect fraction $\eta_{1}+\eta_{2}$ remain constant with increasing $\alpha^{\prime}$-martensite fraction.

\section{DISCUSSION}

It has been reported that the deformation mechanisms responsible for the mechanical properties of austenitic Mn-based TWIP steels are related to the austenite $(\gamma)$ stability and involve dislocation slip, twinning, and plasticity-induced transformation to martensite. ${ }^{[1-7]}$ With increasing $\varepsilon_{e q}^{a c}$, deformation is facilitated initially by dislocation multiplication, followed by twinning or martensitic transformations, providing barriers for further dislocation slip. ${ }^{[1-7]}$

Austenite with a relatively low stability can transform by means of $\gamma \rightarrow \varepsilon \rightarrow \alpha^{\prime}$ martensitic transformations, resulting in a high work-hardening rate. Stability against $\gamma \rightarrow \varepsilon$-martensite transformation often implies stability against $\gamma \rightarrow(\varepsilon \rightarrow) \alpha^{\prime}$-martensite transformation. ${ }^{[19,20]}$ According to Olson and Cohen, ${ }^{[15,16]}$ however, a low SFE promotes strain-induced nucleation of $\alpha^{\prime}$-martensite, but does not necessarily require the intermediate formation of $\varepsilon$-martensite. XRD confirmed the absence of $\varepsilon$-martensite. Magnetic measurements revealed the formation of small volume fraction $\alpha^{\prime}$-martensite at $\varepsilon_{e q}^{a c} \geq 0.6$ (resulting from deep drawing). This fraction was too low for XRD to detect. The fact that $\alpha^{\prime}$-martensite, indeed, is formed without the presence of $\varepsilon$-martensite rules out the $\gamma \rightarrow \varepsilon \rightarrow \alpha^{\prime}$ martensitic transformation sequence, which implies $\alpha^{\prime}$-martensite formation in high SFE material.

In Mn-based TWIP steels, $\alpha^{\prime}$-martensite is known to form at the intersections of shear bands such as slip bands, twins, or $\varepsilon$-martensite laths. ${ }^{[15,16]}$ These intersected shear bands can be very effective as nucleation sites, allowing the passage of previously blocked dislocations, inducing the formation of $\alpha^{\prime}$-martensite, ${ }^{[15,16]}$ and releasing stress concentrations. ${ }^{[10]}$

The $\alpha^{\prime}$-martensite formation can be attributed to the magnitude of $\varepsilon_{e q}^{a c}$, providing the required density of shear band intersections and high stress concentrations. Liang et $a l^{[5]}$ also indicated the importance of the strain path for the microstructural evolution. Oh et al. ${ }^{[10]}$ also observed the sequential formation of deformation twins and $\alpha^{\prime}$-martensite, which corresponds to the occurrence of intersections and consequent $\alpha^{\prime}$ formation at larger $\varepsilon_{e q}^{a c}$ (in the present study due to deep drawing). The strain occurring in tensile straining (also in the case of "deep drawing" at $10 \mathrm{~mm}$ from the cup bottom) is too small to induce $\alpha^{\prime}$ formation.

Because the intersections only account for a small fraction of the material, a relatively low $\alpha^{\prime}$-martensite fraction is formed, as observed in Figure 3. Based on their theory of embryo formation by strain, Olson and Cohen ${ }^{[16]}$ proposed the following relation for the evolution of $\alpha^{\prime}$-martensite volume fraction upon straining:

$$
f_{\alpha^{\prime}}^{O C}=1-\exp \left\{-\beta^{O C}\left[1-\exp \left(-\alpha^{O C} \cdot \varepsilon_{e q}^{a c}\right)\right]^{n}\right\}+f_{0}
$$

where $\alpha^{O C}$ and $\beta^{O C}$ are two physically significant, temperature-dependent parameters; $\varepsilon_{e q}^{a c}$ is the accumulated equivalent strain; $n$ is a fixed exponent, with a suggested value $n=2$; and $f_{0}$ is the initial $\alpha^{\prime}$-martensite fraction. We introduce $f_{0}$ in order to consider the initial $\alpha^{\prime}$-martensite fraction. The orientation of the shear bands will not be random, but will tend to be initially parallel until secondary shear systems start to form. The formation of primary and secondary shear systems is not arbitrary and shows a sequential nature upon straining, increasing the number of intersections exponentially. Olson and Cohen ${ }^{[16]}$ claimed that this behavior can be approximated by applying a higher exponent than $n=2$, and found that $\beta^{O C}=1.18$ and $n=4.5$ gave the best overall results. Using their $\beta^{O C}$ and $n$, Figure 3 shows that for $\alpha^{O C}=0.48$, the fit is in good agreement with the experimental results. Note that the fit includes an initial $\alpha^{\prime}$-martensite fraction of $f_{0}=2 \cdot 10^{-3}$.

In this work, we propose a similar approach for $\alpha^{\prime}$-martensite volume fraction evolution upon straining, in particular, the sequential nature of the formation of primary and secondary shear systems upon straining. The proposed model describes the same physical process, but with a slightly different approach, making the use of $n>2$ as artificial approximation of the sequential behavior of primary and secondary shear systems upon straining redundant. Figure 7 gives a schematic illustration for the formation of $\alpha^{\prime}$-martensite. The intersected area $A_{\text {int }}$ is defined as

$$
A_{\text {int }}=\frac{d^{2}}{\sin (\theta)}
$$

with $d$ the average width of a shear band (slip band, twin, or $\varepsilon$-martensite lath) and $\theta$ the angle between the primary and secondary shear systems (Figure 7).

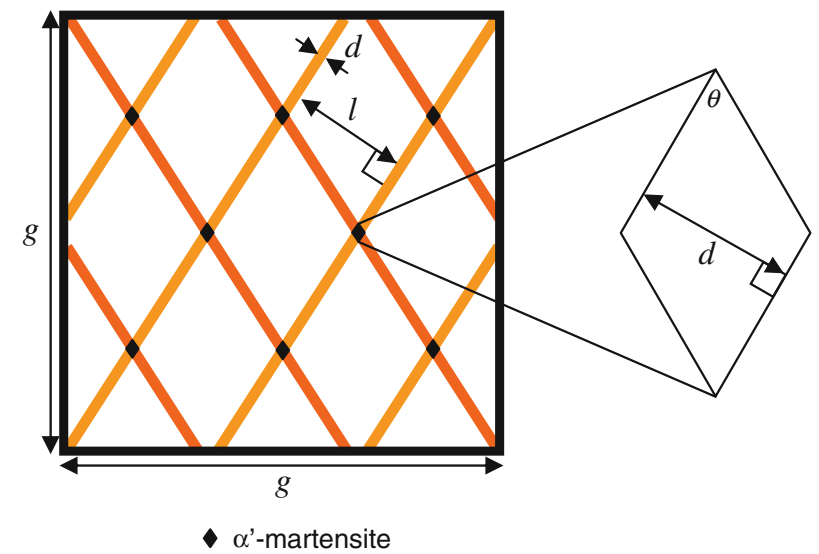

Fig. 7-Schematic illustration for the formation of $\alpha^{\prime}$-martensite at intersections of shear bands (slip bands, twins, or $\varepsilon$-martensite laths). 
The volume fraction of intersected shear bands $f_{\text {int }}^{T w}$ can be estimated by

$$
f_{\text {int }}^{T w}(d, l)=\left(\frac{d}{d+l}\right)^{2}
$$

where $l$ is the average distance between two shear bands of a shear system and $g$ is the grain size, which is canceled out in Eq. [7]. The volume fraction of intersected shear bands is related to the ratio between $d$ and $l$ and is independent of their absolute values. According to Elhami et al., ${ }^{[21]}$ the deformation mode influences the number and size of twins. In the literature, ${ }^{[20]}$ the mean twin width is assumed to be $0.03 \mu \mathrm{m}$, leaving the average distance between two shear bands of a shear system as the remaining parameter. As Olson and Cohen ${ }^{[16]}$ pointed out, the formation of primary and secondary shear systems is not arbitrary and shows a sequential nature upon straining. This sequential behavior requires the introduction of Eq. [8]. Equation [7], therefore, can be rewritten as $\alpha^{\prime}$-martensite volume fraction evolution upon straining:

$$
f_{\alpha^{\prime}}^{T w}=f_{0}+p\left(\frac{d}{d+l_{1}}\right) \cdot\left(\frac{d}{d+l_{2}}\right)
$$

where $l_{1}$ is the average distance between two shear bands of the primary shear system, $l_{2}$ is the average distance between two shear bands of the secondary shear system, and $p$ is the probability for nucleation of $\alpha^{\prime}$-martensite at the shear band intersection. Taking into account the sigmoidal shape of $\alpha^{\prime}$-martensite formation upon straining, $l_{1}$ and $l_{2}$ can be defined as

$$
l_{1}=g \cdot \exp \left(-\alpha^{T w} \cdot \varepsilon_{e q}^{a c}\right)
$$

and

$$
l_{2}=g \cdot \exp \left(-\alpha^{T w} \cdot\left(\varepsilon_{e q}^{a c}-\varepsilon_{\alpha^{\prime}}\right)\right) \varepsilon_{e q}^{a c}>\varepsilon_{\alpha \prime},
$$

where $\alpha^{T w}$ is a fitting parameter and $\varepsilon_{\alpha^{\prime}}$ is the strain at which $\alpha^{\prime}$-martensite formation starts. Fitting the experimental results of Figure 3 for $d=0.03 \mu \mathrm{m},{ }^{[20]}$ $g=5 \mu \mathrm{m}, \alpha^{T w}=9$, and $\varepsilon_{\alpha^{\prime}}=0.2$ leads to a probability $p=0.03$.

The comparison between the proposed model and the Olson-Cohen model does not proclaim a clear preference. However, the proposed model does not require the artificial approximation of the sequential behavior upon straining, but describes this behavior according to the geometrical model put forward by Olson and Cohen. ${ }^{[15]}$ Fitting this model reveals a very low probability for nucleation of $\alpha^{\prime}$-martensite at shear band intersections, confirming the physical meaning of this approach.

The accumulated equivalent strain $\varepsilon_{e q}^{a c}$ is suggested as a relevant measure of strain, enabling the comparison between tensile straining and deep drawing. With increasing $\varepsilon_{e q}^{a c}$, deformation is facilitated by dislocation multiplication, dislocation glide, and twinning, providing the required intersections of shear bands for eventual $\alpha^{\prime}$-martensite formation at high $\varepsilon_{e g}^{a c}$. Therefore, it is suggested that the appropriate deformation mechanisms, in particular the formation of $\alpha^{\prime}$-martensite, can be related to $\varepsilon_{e q}^{a c}$.

\section{CONCLUSIONS}

In this work, magnetic measurements, $\mathrm{XRD}$, positron beam Doppler spectroscopy, and finite element method simulations were used to investigate the relation between the strain and the deformation mechanisms in an austenitic Mn-based TWIP steel in tensile deformation and deep drawing. Despite its high SFE, deep-drawing results in the formation of $\alpha^{\prime}$-martensite, whereas tensile straining does not. This effect is attributed to the larger accumulated equivalent strain resulting from deep drawing as compared to tensile straining. A model for $\alpha^{\prime}$-martensite volume fraction evolution upon straining is proposed and the estimated fraction of intersected shear bands - the preferred nucleation sites for $\alpha^{\prime}$-martensite formation - as a function of accumulated equivalent strain is in good agreement with the experimentally determined $\alpha^{\prime}$-martensite fraction.

\section{ACKNOWLEDGMENTS}

This research was carried out under Project No. MC5.07292 in the framework of the Research Program of the Materials Innovation Institute (M2i) (www.m2i.nl). The authors thank J. Brussel and M. de Bruine (Tata Steel) for their technical support with, respectively, the tensile and deep-drawing experiments. The authors also thank N. van der Pers for performing the XRD experiments, P. Kömmelt (Tata Steel) for performing the FEM simulations, and F. Twisk (Tata Steel) and Dr. P. Romano (Tata Steel) for performing the SEM.

\section{OPEN ACCESS}

This article is distributed under the terms of the Creative Commons Attribution License which permits any use, distribution, and reproduction in any medium, provided the original author(s) and the source are credited.

\section{REFERENCES}

1. D. Cornette, P. Cugy, A. Hildenbrand, M. Bouzekri, and G. Lovato: SAE Conf, Detroit, MI, 2005, pp. 1-13.

2. C. Scott, N. Guelton, S. Allain, and M. Faral: Mater. Sci. Technol., 2005, pp. 127-38.

3. C. Efstathiou and H. Sehitoglu: Acta Mater., 2010, vol. 58, pp. $1479-88$

4. D. Barbier, N. Gey, S. Allain, N. Bozzolo, and M. Humbert: Mater. Sci. Eng. A, 2009, vol. 500, pp. 196-206.

5. X. Liang, J.R. McDermid, O. Bouaziz, X. Wang, J.D. Embury, and H.S. Zurob: Acta Mater., 2009, vol. 57, pp. 3978-88.

6. S. Curtze and V.-T. Kuokkala: Acta Mater., 2010, vol. 58, pp. $5129-41$.

7. G. Frommeyer, U. Brüx, and P. Neumann: ISIJ Int., 2003, vol. 43 (3), pp. 438-46. 
8. W. Bleck, K. Phiu-on, C. Heering, and G. Hirt: Steel Res. Int., 2007, vol. 78 (7), pp. 536- 46.

9. P.C.J. Gallagher: Metall. Trans., 1970, vol. 1, pp. 2429-61.

10. B.W. Oh, S.J. Cho, Y.G. Kim, W.S. Kim, and S.H. Hong: Mater. Sci. Eng. A, 1995, vol. 197, pp. 147-56.

11. H. Vegter and A.H. van den Boogaard: Int. J. Plast., 2006, vol. 22, pp. $557-80$.

12. L. Zhao, N.H. van Dijk, E. Brück, J. Sietsma, and S. van der Zwaag: Mater. Sci. Eng. A, 2001, vol. 313, pp. 145-52.

13. H. Schut: Ph.D. Thesis, Delft University of Technology, Delft, 1990.

14. R. Krause-Rehberg and H.S. Leipner: Positron Annihilation in Semiconductors-Defect Studies, Springer Verlag, Berlin, Germany, 1999.
15. G.B. Olson and M. Cohen: J. Less-Common Met., 1972, vol. 28, pp. $107-18$.

16. G.B. Olson and M. Cohen: Metall. Trans. A, 1975, vol. 6A, pp. 791-95.

17. R.T. van Tol, L. Zhao, H. Schut, and J. Sietsma: Mater. Sci. Technol., 2012, vol. 28 (3), pp. 348-53.

18. L. Bracke: Ph.D. Thesis, University of Ghent, Ghent, 2007.

19. S. Allain, J.-P. Château, O. Bouaziz, S. Migot, and N. Guelton: Mater. Sci. Eng. A, 2004, vols. 387-389, pp. 158-62.

20. O. Bouaziz, S. Allain, C.P. Scott, P. Cugy, and D. Barbier: Curr. Opin. Solid State Mater. Sci., 2011, pp. 141-68.

21. N. Elhami, S. Zaefferer, I. Thomas, and H. Hofmann: 1st Int. Conf. on High Mn TWIP Steels HMnS2011, Seoul, South Korea, May 2011. 